\title{
Protocol for monitoring standing crop in grasslands using visual obstruction
}

\author{
LAKHDAR BENKOBI, DANIEL W. URESK, GREG SCHENBECK, AND RUDY M. KING
}

Authors are Research Scientist, Department of Rangeland Ecosystem Science, Colorado State Univ., Fort Collins, Colo. 80523, Supervisory Research Biologist, USDA Forest Service, Rocky Mountain Research Station, Center for Great Plains Ecosystem Research, School of Mines Campus, Rapid City, SD 57701, Wildlife Biologist, USDA Forest Service, Nebraska National Forest, Chadron, Neb. 69377, and Station Statistician, USDA Forest Service, Rocky Mountain Research Station, Fort Collins, Colo. 80526, respectively.

\section{Abstract}

\begin{abstract}
Assessment of standing crop on grasslands using a visual obstruction technique provides valuable information to help plan livestock grazing management and indicate the status of wildlife habitat. The objectives of this study were to: (1) develop a simple regression model using easily measured visual obstruction to estimate standing crop on sandy lowland range sites in the Nebraska Sandhills, (2) provide sampling and monitoring suggestions in the use of visual obstruction on this grassland type, and (3) compare the visual obstruction technique to the standard clip and weigh procedure. Visual obstruction precisely predicted average standing crop dry weights for the sandy lowland range sites $\left(\mathbf{r}^{2}=\right.$ 0.88 ). A prediction accuracy of $\pm 295 \mathrm{~kg} \mathrm{ha}^{-1}$ was found using a test data set. Two sampling options (A and $B)$ were evaluated using a 2-stage sampling protocol. Option A (1 transect/quarter section) provided more precise estimates applicable to extensive grasslands than option B. However, option A was not applicable to a section ( 259 ha) or a few sections. Option B (3 transects/section) provided estimates applicable to each section and to the entire area, but it required more intensive sampling than option A to attain the same precision. The visual obstruction technique provided more precise estimates of standing crop than the standard clip and weigh technique when clipping and weighing up to 6 plots per transect. When 7 or more clipped and weighed plots per transect were sampled, standing crop estimates were more precise than using visual obstruction readings. However, since 20 visual obstruction readings/transect ( 25 minutes) can be sampled in about half the time spent clipping and weighing 6 plots/transect (45 minutes), visual obstruction in combination with a previously estimated regression model provides a simple, reliable, and cost effective alternative to the clip and weigh technique. Regression models should be developed for other grassland types following the methodology described in this paper.
\end{abstract}

Key Words: Residual cover, grassland structure, regression model, wildlife habitat, Robel pole, Nebraska Sandhills

Herbage standing crop on grasslands is valued for multiple uses such as livestock production, wildlife food and cover, and soil protection against erosion. Assessment of grassland standing crop using a visual obstruction technique provides important informa-

Research was partially funded by Nebraska National Forest under cooperative agreement number 28-A3-746. Authors wish to thank Drs. C. D. Bonham, W. C. Krueger, R. J. Robel, M. J. Trlica, and D. Turner for reviewing this manuscript. Manuscript accepted 7 Mar. 2000.

\section{Resumen}

La evaluación del forraje en pie del pastizal utilizando la técnica de obstrucción visual provee valiosa información que ayuda a planear el manejo del apacentamiento del ganado e indicar el estado del h·bitat de la fauna silvestre. Los objetivos de este estudio fueron: (1) desarrollar un modelo de regresión simple utilizando la obstrucción visual simple (que es f•cil de medir) para estimar el forraje en pie en sitios de pastizal de tierras bajas arenosas en los pastizales "Nebraska "Sandhills", (2) proveer sugerencias sobre el muestreo y monitoreo con el uso de la técnica de obstrucción visual en este tipo de pastizales y (3) comparar la técnica de obstrucción visual con la técnica de cortar y pesar. La obstrucción visual predijo en forma precisa el promedio de peso seco de la producción de forraje en pie de los sitos de pastizal de tierra baja arenosa $\left(r^{2}=0.88\right)$. Con el conjunto de datos experimentales utilizados se encontró una certeza de predicción de $\pm 295 \mathrm{~kg} \mathrm{ha}^{-1}$. Se evaluaron dos opciones de muestreo utilizando un protocolo de muestreo de dos etapas. La opción A (1 transecto/cuarto de sección) produjo estimaciones mas precisas aplicables a pastizales extensivos que las estimaciones obtenidas con la opción B. Sin embargo, la opción A a no fue aplicable a una sección (259 ha) o a unas pocas secciones. La opción B (3 transecto/sección) rindió estimaciones aplicables a cada sección y el áea entera, pero requirió un muestreo mas intensivo que la opción $\mathbf{A}$ para obtener la misma precisión. La técnica de obstrucción visual produce estimaciones mas precisas del forraje en pie que la técnica de corte y peso cuando se cortan y se pesan hasta 6 cuadrantes por transecto. Cuando se cortan y pesan 7 o mas cuadrantes por transecto las estimaciones del forraje en pie fueron mas precisas que las obtenidas con la obstrucción visual. Sin embargo, dado que 20 lecturas/transecto de la técnica de obstrucción visual ( 25 minutos) pueden ser obtenidas en casi la mitad del tiempo utilizado para cortar y pesar 6 cuadrante/transecto (45 minutos), la obstrucción visual en combinación con un modelo de regresión previamente estimado provee un alternativa mas simple, confiable y menos costosa que la técnica de corte y peso. Los modelos de regresión deben ser desarrollados para otros tipos de pastizales siguiendo la metodología descrita en este artáculo.

tion to plan livestock grazing management and to evaluate habitat conditions for various grassland wildlife species (Webb 1942, Slade et al. 1965, Higgins and Barker 1982, Higgins 1986).

For decades, a common method to obtain standing crop dry weight estimates has been the double sampling method (Pechanec and Pickford 1937). This method consists of visually estimating 
herbage weight for a large number of plots. A portion of these plots are visually estimated and the herbage is clipped. The clipped herbage is oven dried and weighed. Oven dried weights are then used to correct visual estimates through a regression model. This technique can be costly and time consuming as large sample sizes may be required to produce precise estimates.

Several non-destructive techniques, such as the biometer (Pearson and Miller 1972), the Massey grass meter (Holmes 1974), the Ellinbank pasture meter (Earle and McGowan 1979), and the rising plate meter (Michell and Large 1983, Gabriëls and Van Den Berg 1993), have provided estimates of standing crop with high degrees of accuracy. However, they were not designed to measure vegetation visual obstruction, a height-density measurement that relates to values of the environment in which wildlife live (Webb 1942, Robel et al.1970, Higgins and Barker 1982, Higgins 1986).

Visual obstruction can be used to estimate the amount of standing crop dry weight as an alternative to clipped plots to minimize cost and effort for monitoring grasslands. Standing crop dry weight estimates can be indirectly obtained using easily measured visual obstruction (Robel et al. 1970) in regression models. The status of wildlife habitat can be quantified using visual obstruction as an estimate of vegetation height-density (Webb 1942, Robel 1966, Higgins and Barker 1982, Higgins 1986).

The rationale for using visual obstruction to monitor standing crop and vegetation height-density on grasslands is based on the simplicity of this technique, dual measurements obtained from each use of the pole (vegetation dry weight for livestock production and height-density for wildlife habitat status), and application over broad areas with less effort (no clipping and bagging and no drying and weighing) than the standard clip and weigh procedures. Our purpose was to develop simple regression models to use easily measured visual obstruction to accurately predict average amounts of standing crop for livestock management and simultaneously determine the status of grasslands for wildlife habitat. The objectives were: (1) to develop and test models used to estimate grassland standing crop using a graduated pole, (2) compare the time spent (cost) and efficiency of the visual obstruction technique versus the clip and weigh technique, and (3) determine sampling intensities and monitoring guidelines needed to use visual obstruction on grasslands for standing crop dry weight and vegetation height-density assessments.

\section{Materials and Methods}

\section{Study Area}

This study was conducted on the Samuel R. McKelvie National Forest (SMNF) located $43 \mathrm{~km}$ southwest of Valentine, Nebraska $\left(42^{\circ} \mathrm{N}, 101^{\circ} \mathrm{W}\right)$. This area includes sand dune hills, sandy basins, and valleys that are stabilized by vegetation (Bleed and Flowerday 1990). The study, however, focused on the vegetation in the sandy lowland range sites where native graminoids dominate. Little bluestem (Schizachyrium scoparium Michx.), prairie sand reed (Calamovilfa longifolia Hook.), and needle-and-thread (Stipa comata Trin. \& Rupr.) are the dominant species. Other common species include sun sedge (Carex spp. Mack.), sand bluestem (Andropogon hallii Hack.), hairy grama (Bouteloua hirsuta Lag.), blue grama (Bouteloua gracilis H.B.K.), switchgrass (Panicum virgatum L.), Kentucky bluegrass (Poa pratensis L.), sand lovegrass (Eragrostis trichodes Nutt.), sand dropseed (Sporobolus cryptandrus Torr.), and common ragweed (Ambrosia artemisiifolia L.). Soils belong to the Ipage and Inavale loamy fine sand series with 0 to $3 \%$ slopes (USDA-SCS 1993). Elevations range from 1,219 to $1,310 \mathrm{~m}$ above sea level, rising gradually from east to west. Average annual precipitation is $436 \mathrm{~mm}$, most of it falling from April to September. Precipitation from October to March falls as snow. The mean annual temperature is $8.3^{\circ} \mathrm{C}$. Average maximum temperature is $16^{\circ} \mathrm{C}$ and average minimum temperature is $1^{\circ} \mathrm{C}$. The average frost-free period is 150 days (National Climate Data Center 1993).

\section{Data Collection and Analyses}

Visual obstruction and clipped vegetation data were collected in the fall of 1996 after a killing frost. A modification of the pole described by Robel et al. (1970) was used to measure visual obstruction and a $0.25 \mathrm{~m}^{2}$ circular quadrat was used to clip and harvest vegetation. The width of alternating grey and white bands on the pole was modified from $1 \mathrm{dm}$ to $2.54 \mathrm{~cm}$ wide. The bands were numbered beginning with 1 at the bottom. The bottom of the pole had a $15 \mathrm{~cm}$ spike which allowed it to stand free once the spike was pushed into the ground. The graduated pole was placed in the center of the circular quadrat and visual obstruction readings (VORs) were made from a distance of $4 \mathrm{~m}$ with the reader's eyes at a height of $1 \mathrm{~m}$ (Robel et al. 1970). The top band totally obstructed was recorded as a reading. If the first band was visible, the reading was zero. A reading of 1 meant that the first band was totally obstructed by vegetation. At each measurement station, 4 VORs were recorded, 1 for each cardinal direction. The 4 VORs were averaged for each station and multiplied by 2.54 to convert to centimeters.

A stratified sampling design (Cochran 1977, Cook and Stubbendieck 1986) was used to collect vegetation (live and dead) data. Strata were structured so that an equal number of pastures representing tall to very short vegetation were sampled to provide a broad range of data to estimate the regression relationship. The sampling design included 58 pastures (300 to 550 ha each) with 3 randomly located transects per pasture. Along each $200 \mathrm{~m}$ transect, 20 pole stations spaced $10 \mathrm{~m}$ apart were read for visual obstruction and 4 stations were clipped $(50,100,150$, and $200 \mathrm{~m})$ for standing crop estimates. Vegetation within the circular quadrat was clipped at ground level, oven dried at $60^{\circ} \mathrm{C}$ for 48 hours, and weighed to the nearest gram. Standing crop was expressed in $\mathrm{kg} \mathrm{ha}^{-1}$.

Regression was used to quantify the relationship between visual obstruction and standing crop. The average of the VORs for each transect was the independent variable and the average of the 4 standing crop estimates was the dependent variable. Probability plots were used to examine normality of residuals (Kleinbaum and Kupper 1978, Afifi and Clark 1990). Prediction accuracy of the developed regression model was checked at the 0.05 level of significance using methods outlined by Freese (1960) for a separate data set (average dry weight $=$ $913 \mathrm{~kg} \mathrm{ha}^{-1}$ with $\mathrm{SE}=104$, average VOR $=4.82 \mathrm{~cm}$ with $\mathrm{SE}=0.62$, and $\mathrm{n}=19$ transects) that was collected in the fall of 1996. The transects were randomly located within 19 pastures ( 1 transect/pasture).

\section{Sampling Intensity}

Estimation of sample size for future applications of visual obstruction was based on within and between transect variability in the grassland. The average visual obstruction for each transect was obtained from reading 20 stations. The number of transects needed to achieve estimates within \pm $20 \%$ of the actual mean with an $80 \%$ confidence interval was estimated for each pasture. A box-and-whisker plot 
(Chambers et al. 1983) was used to display the required number of transects. The required number of sampling stations per transect was estimated using a reading precision of half a band $(1.27 \mathrm{~cm})$ on the graduated pole with an $80 \%$ confidence level. Cochran's (1977) method for sample size estimation for continuous data was used for both analyses. A Box-Ljung test (Cryer 1986) was used to assess the significance of serial correlation among consecutive sampling stations to estimate the minimum recommended interval between stations along a transect. Variance component estimation (SAS Institute 1989) was used to compare the variability among reading directions per station to the variability among stations per transect to determine whether multiple readings per station were required.

\section{Sampling Alternatives}

The size of area (percentage of total land base) to be sampled to monitor the grassland with the pole was estimated by

$$
n=\left(\frac{t S}{E}\right)^{2} /\left(1+\left(\frac{1}{N}\left(\frac{t S}{E}\right)^{2}\right)\right.
$$

(Cochran 1977), where $n$ is the estimated number of management units to be sampled (a management unit was approximately equal to a section, $259 \mathrm{ha}$ ), $N$ is the total number of management units to be monitored, $S$ is the estimated variance among management unit means, $t$ is the value for the t-distribution with $n-1$ degrees of freedom and $80 \%$ confidence, and $E$ is the specified fixed error around the mean. The percentage of total land base is derived from the ratio $n / N$.

The percentage of total land base corresponds to the number $(n)$ of primary sampling units. In this case, $n$ refers to the number of sections that would be randomly selected for sampling. Based on the variability of visual obstruction on grasslands in the National Forest (SMNF), we propose 2 options for a 2 -stage cluster sampling protocol, with either a quarter section as a primary sampling unit where 1 transect is used as a single subunit (option A, low sampling intensity for large areas) or a whole section (option $\mathrm{B}$, high intensity sampling for a pasture or a few pastures) as a primary sampling unit where 3 transects are used as subunits. The number $(N)$ of primary units for a total land base is fixed (e.g.181 sections or 724 quarter sections for the SMNF) and the number of possible subunits $(M)$ within each primary unit is assumed to be large (i.e. possible transect locations within a quarter section or a section are numerous). In 2-stage cluster sampling, the first stage is a ran- dom draw of primary units (sections) followed by a second stage random draw of subunits (transects) within each selected primary unit. Estimation of overall mean and variances is presented below for quantitative parameters (e.g. mean visual obstruction) and proportion of residual vegetation (e.g. proportion with VOR < $7.5 \mathrm{~cm}$ ). Notation for overall mean and variance is $N$ primary units, each with $M$ subunits. A sample of $n$ primary units is randomly drawn; $m$ subunits are randomly selected within each primary unit. Let $y_{i j}$ be the sampled visual obstruction for the $j$ th subunit in the $\mathrm{i}$-th primary unit (e.g. VOR for the $j$-th transect in the i-th pasture). Estimators are developed from:

$$
\begin{gathered}
\bar{y}_{i}=\sum_{j=1}^{m} \frac{y_{i j}}{m}, \quad \overline{\bar{y}}=\sum_{i=1}^{n} \frac{\bar{y}_{i}}{n}, \\
s_{1}^{2}=\frac{\sum_{i=1}^{n}\left(\bar{y}_{i}-\bar{y}\right)^{2}}{n-1}, \quad s_{2}^{2}=\frac{\sum_{i=1}^{n} \sum_{j=1}^{m}\left(y_{i j}-\bar{y}_{i}\right)^{2}}{n(m-1)} .
\end{gathered}
$$

$\overline{\bar{y}}$ is the estimate of overall mean VOR. The variance of $\overline{\bar{y}}$ is estimated by:

$$
\begin{aligned}
& v(\bar{y})=\frac{1-f_{1}}{n} s_{1}^{2}+\frac{f_{1}\left(1-f_{2}\right)}{m n} s_{2}^{2}, \\
& \text { where } f_{1}=\frac{n}{m} \text { and } f_{2}=\frac{m}{M}
\end{aligned}
$$

$M$ is assumed to be quite large relative to $m$, such that $f_{2} \approx 0$. Notation for a proportion in a class (e.g. VOR $<7.5 \mathrm{~cm}$ ) is similar except the basic observation is $p_{i}$, the proportion of $m$ subunits falling in a class for the i-th primary unit. Also,

$$
\begin{aligned}
& \bar{p}=\sum_{i=1}^{n} \frac{p_{i}}{n}, \quad s_{1}^{2}=\frac{\sum_{i=1}^{n}\left(p_{i}-\bar{p}\right)^{2}}{n-1}, \\
& s_{2}^{2}=\frac{m}{n(m-1)} \sum_{i=1}^{n} p_{i} q_{i}, \text { where } q_{i}=1-p_{i} .
\end{aligned}
$$

Variance of $\bar{p}$ is estimated by:

$$
v(\bar{p})=\frac{1-f_{1}}{n(n-1)} \sum_{i=1}^{n}\left(p_{i}-\bar{p}\right)^{2}+\frac{f_{1}\left(1-f_{2}\right)}{n^{2}(m-1)} \sum_{i=1}^{n} p_{i} q_{i} .
$$

\section{Time Allocation}

The amount of time spent collecting visual obstruction data averaged 1 min 15 sec per station. For the clip and weigh technique, 1 min $15 \mathrm{sec}$ per station was spent in labeling bags (date, area, allotment, pasture, transect, and station), 5 min $17 \mathrm{sec}$ in harvesting vegetation, and $46 \mathrm{sec}$ for laboratory work (drying, weighing and recording weights, and storing samples) for a total of $7 \mathrm{~min} 28 \mathrm{sec}$ per sample.

\section{Results}

\section{Regression}

The relationship between standing crop and visual obstruction was strongly linear as indicated by the high coefficient of determination $\left(\mathrm{r}^{2}=0.88\right.$, Fig. 1). Examination of probability plots indicated residuals were normally distributed. The regression model predicted the test data with an average error of $\pm 295 \mathrm{~kg} \mathrm{ha}^{-1}$ at a 95\% level of confidence. However, prediction of single values of standing crop will have a greater relative error $(\%)$ with small Visual Obstruction Readings (VORs), but this decreases substantially for larger VORs (Fig. 2). For an estimate of 3,000 kg $\mathrm{ha}^{-1}$, the relative error would be about $10 \%$ which corresponds to an absolute error of $300 \mathrm{~kg} \mathrm{ha}^{-1}$. In contrast, for an estimate of $600 \mathrm{~kg} \mathrm{ha}^{-1}$, the relative error would be about $50 \%$ which corresponds to an absolute error of $300 \mathrm{~kg} \mathrm{ha}^{-1}$. The relative error in estimated standing crop increases substantially for smaller VORs but the absolute error is constant at $300 \mathrm{~kg} \mathrm{ha}^{-1}$ throughout the range of prediction.

\section{Sampling Intensity}

The estimated number of transects needed in each pasture to attain estimates within $\pm 20 \%$ of the mean with an $80 \%$ confidence interval are displayed in Figure 3. Three transects per pasture would attain the precision objective on more than $90 \%$ of the 58 sampled pastures. The number of stations per transect needed to attain an estimate within \pm half a band $(1.27 \mathrm{~cm})$ on the graduated pole with an $80 \%$ confidence interval can be obtained using Figure 4. Once a preliminary estimate of vegetation visual obstruction is obtained for the entire area to be sampled, the number of sampling stations per transect can be read by matching the number of stations with the estimated VOR. A more conservative approach would be to estimate the number of sampling stations based on the transect average of highest VORs contained in the area. For the entire national forest (SMNF), the average of high VORs was about $10 \mathrm{~cm}$ which matched with 20 stations per transect (Fig. 4). Serial correlations among consecutive sampling stations along a transect indicated that a $10 \mathrm{~m}$ interval was long enough for observations to be uncorrelated ( $p>$ 0.05 ) for about $90 \%$ of the transects for 


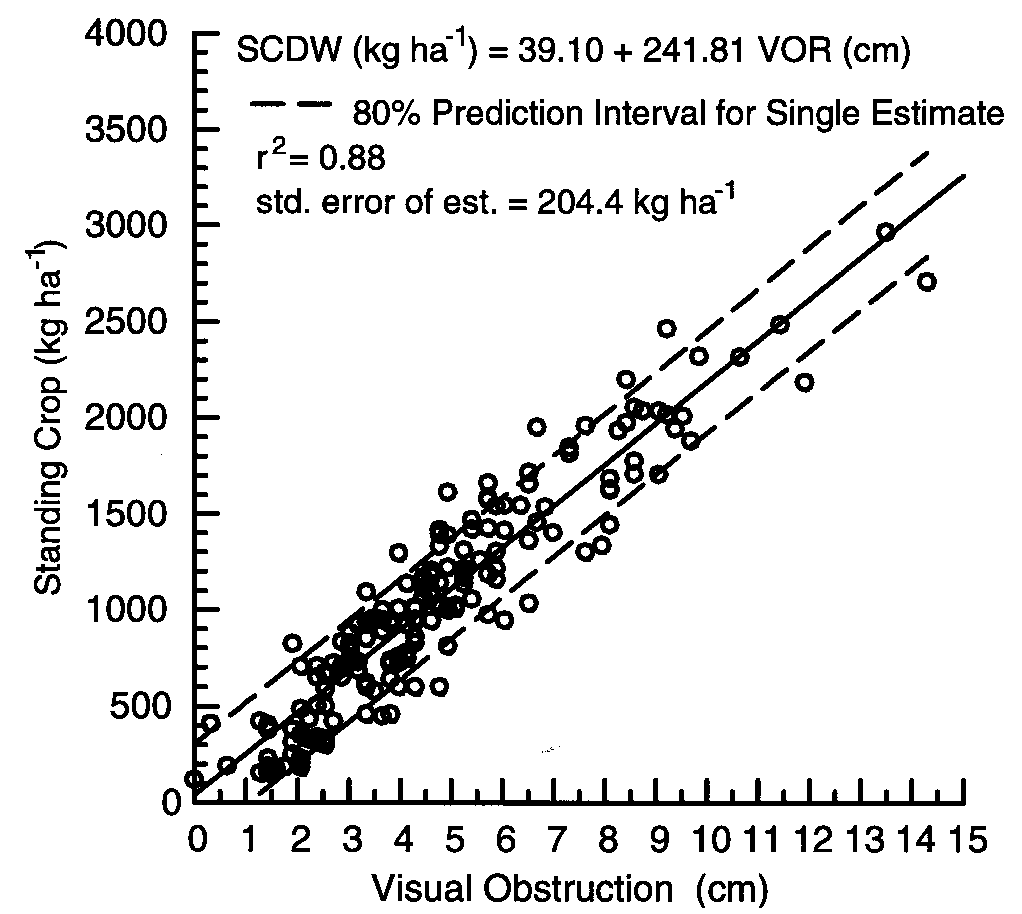

Fig. 1. Scatter plot of standing crop $\left(\mathrm{kg} \mathrm{ha}^{-1}\right)$ on a dry weight (SCDW) versus visual obstruction readings $(\mathrm{cm})$ with associated regression model and $80 \%$ prediction intervals for a single estimate.

the first three intervals $(10,20$, and $30 \mathrm{~m}$ between stations) under a null hypothesis of random pattern. Variance component analysis showed that $89 \%$ of the transects required 4 readings at each station to produce reliable VORs.

\section{Sampling Alternatives}

Estimated fractions of total land base that need to be sampled to attain a precision on mean VOR of $\pm 1.27 \mathrm{~cm}$ with an $80 \%$ confidence level are displayed in Figure 5. Because the magnitude of change in the iterative estimates of sampling fractions were getting substantially smaller after $10 \%$, the inflection point, a sampling fraction of $10 \%$ or higher is recommended for areas 15,000 ha and larger.

For the compared options (A and B) within a 2-stage cluster sampling protocol, mean VOR was $\overline{\bar{y}}=4.74 ; s_{1}{ }^{2}=5.23 ; s_{2}{ }_{2}$ $=1.95$, where $s_{1}{ }^{2}$ was the variance among primary units and $s_{2}{ }^{2}$ the variance among subunits. This assumed pastures were the primary sampling units $(n=58)$ and transects the subunits $(m=3)$. There are 46,929 ha on the SMNF. Assuming a pasture approximately equals a section (259 ha), then $N=181$ sections, or

$$
f_{1}=\frac{n}{N}=\frac{58}{181}=0.32 \text {, }
$$

and $v(\overline{\bar{y}})=0.0613(94.46 \%)+$ $0.0036(5.54 \%)=0.065$, or a standard error of 0.25 . The percentages indicate the amount of total variance associated with primary and subunits. For the SMNF, the variance was almost totally from variation among primary units, apparently because of relatively homogeneous visual obstruction within pastures. The average proportion of transects representing residual vegetation (on grazed area) with VOR $<7.5$ cm was $p=0.69$, with variance $v(\bar{p})=$ $0.00083(83 \%)+0.00017(16 \%)=0.001$ or a standard error of 0.032 .

Assuming that variability among and within primary sampling units is comparable to the variability observed using SMNF 1996 data, alternative sampling plans can be evaluated by specifying appropriate $N, n$, and $m$. Different levels of variability could also be specified if appropriate (and known). For example, applying option A (1 transect/quarter section) to the SMNF would mean $N=724, n$ $=72$ (10\% sample), $m=1$ (treating quarter sections as primary units and transects as single subunits), $s_{1}{ }^{2}=5.23$ and $v(\overline{\bar{y}})=$ 0.0654 . Estimation of a proportion for $m=$ 1 would use simple random sampling methodology resulting in $v(\bar{p})=0.03$. Applying option B (3 transects/section), $N$ $=181, n=18$ (10\% sample), $m=3$ (treating sections as primary units and transects as single subunits), $v(\overline{\bar{y}})=0.261+0.003$ $=0.264$, and $v(\bar{p})=0.11$. Option A (using $10 \%$ out of 724 quarter sections) allowed the target $N$ (the number of primary sampling units) to increase 4 times (1 section $=4$ quarter sections) which required that 72 randomly located transects be sampled throughout the total land base. Option B (using $10 \%$ out of 181 sections) resulted in the requirement that 18 sections, as randomly located primary units, be sampled throughout the total land base with 3 transects per section as subunits. Option A produced a more precise overall estimate of average visual obstruction and overall (not

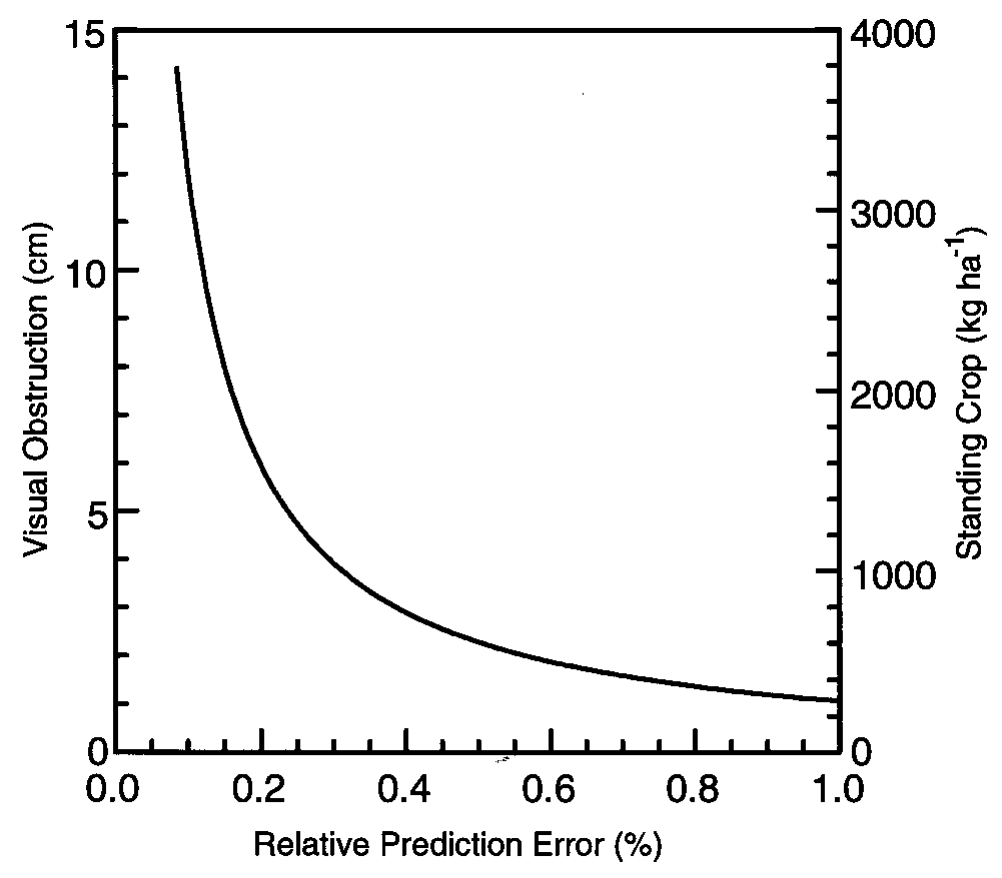

Fig. 2. Estimated prediction error associated with visual obstruction readings and predicted standing crop. 


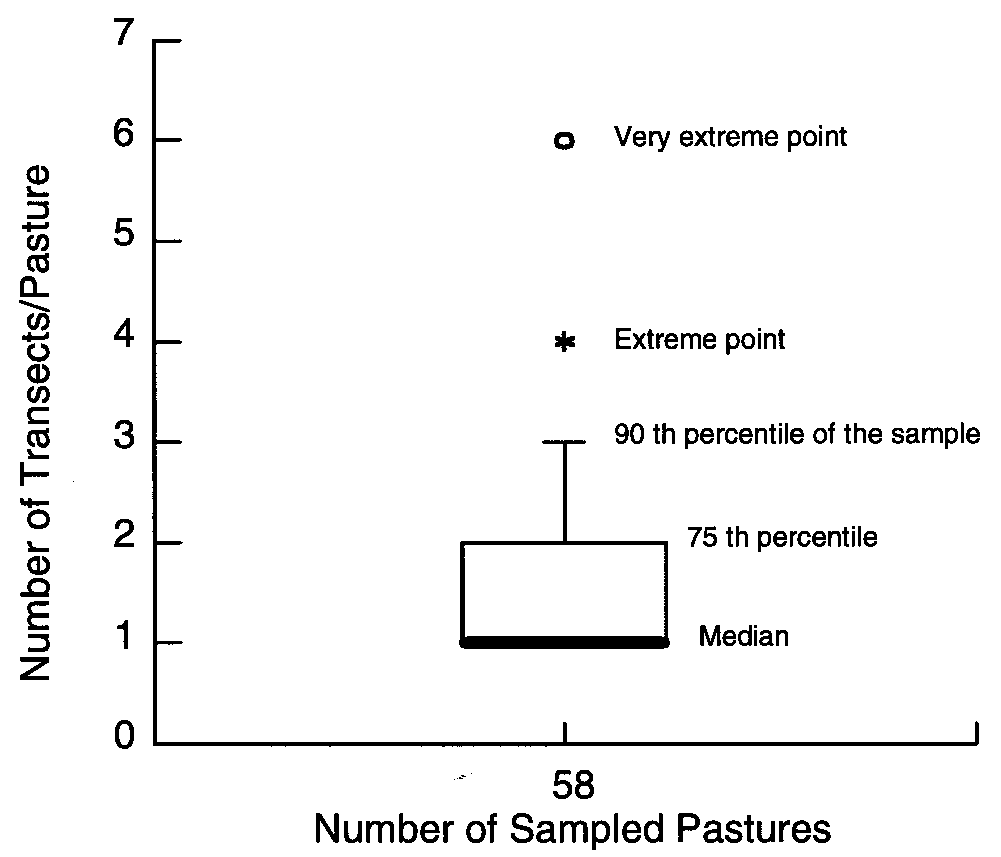

Fig. 3. Estimated number of transects per section for 58 sampled pastures required to attain a precision of $\pm 20 \%$ of the mean VOR with an $80 \%$ confidence level. The median required sample size was one which extended over $50 \%$ of the sampled area. However, 3 transects per pasture or section were adequate for $95 \%$ of the sampled area.

average) $p$ applicable to the entire area, but not applicable to a section (259 ha) or a few sections. Option B provided estimates applicable to each section and to the entire area $(46,929 \mathrm{ha})$, but it would require more

intensive sampling than option A to attain the same level of precision.

\section{Time Allocation}

The recorded time ratio (visual obstruc-

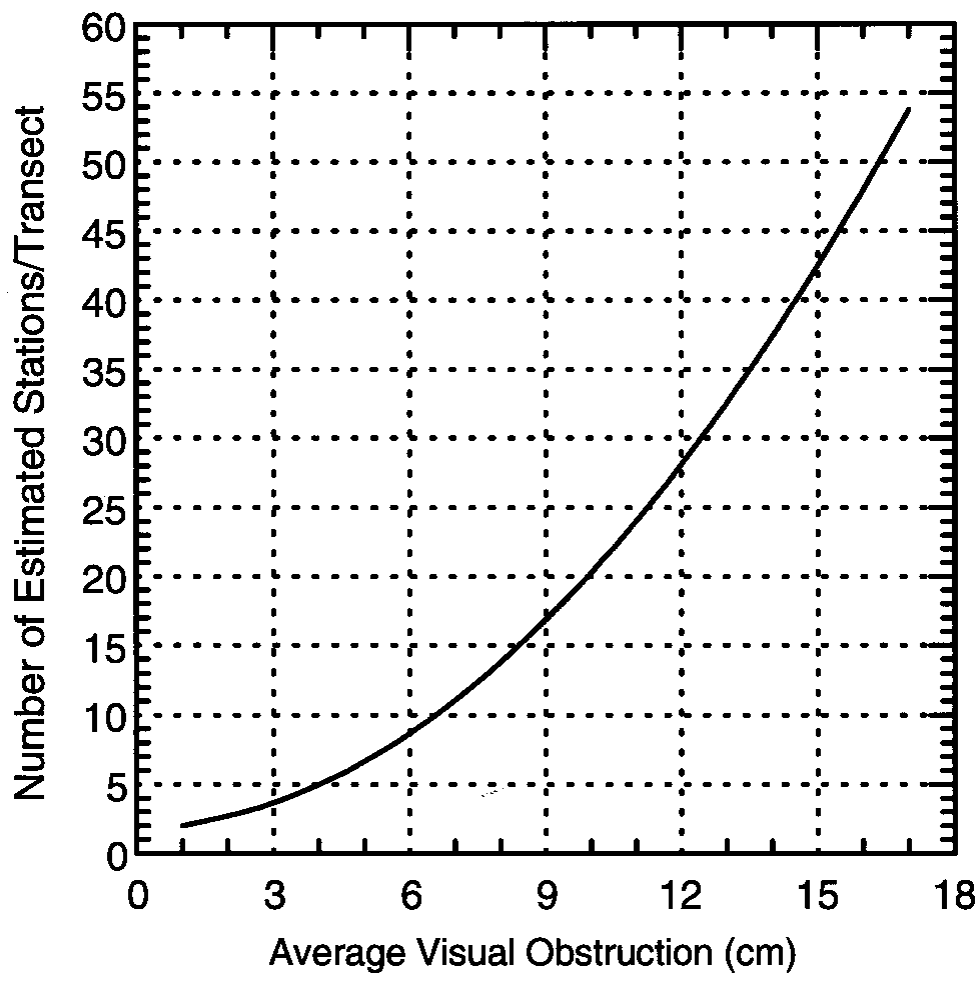

Fig. 4. Number of sampling stations for an individual transect to attain a reading precision of \pm half a band $(1.27 \mathrm{~cm})$ on the graduated pole with an $80 \%$ confidence level. tion versus clip and weigh technique) was evaluated at $1 \mathrm{~min} 15 \mathrm{sec}$ : $7 \mathrm{~min} 28 \mathrm{sec}$. To compare the 2 field sampling techniques in a framework in which only 1 technique would be used, we assumed that visual obstruction would be used in a previously-determined regression model to estimate standing crop for each transect. This allowed estimation of comparable standard errors. The effect of using a Visual Obstruction Reading (VOR) in a regression model to estimate standing crop was evaluated in a measurement error model (Fuller 1987) that included a component for the variability in the regression model relating visual obstruction and standing crop, a component for the variability in VORs taken along a transect, and a component for the variability in clipped and weighed standing crop. For 6 or fewer clipped and weighed plots per transect, visual obstruction estimates were more precise for our data (Fig. 6). For 7 or more clipped and weighed plots per transect, clipped and weighed estimates were more precise, regardless of the number of visual obstruction stations sampled.

\section{Discussion}

Regression results showed that visual obstruction was highly related to standing crop. Prediction of average standing crop was made with high accuracy and precision. However, the relative error of prediction was large for small Visual Obstruction Readings (VORs), while the absolute error remained constant throughout the range of prediction at $300 \mathrm{~kg} \mathrm{ha}^{-1}$. Therefore, the lowest prediction of standing crop to be considered for management purposes should be limited to $300 \mathrm{~kg} \mathrm{ha}^{-1}$. Furthermore, pastures in the Sandhills area, with standing crop equal to or less than $300 \mathrm{~kg} \mathrm{ha}^{-1}$ (which correspond to a VOR of about $1.3 \mathrm{~cm}$ ), visually show little vegetation to require a measurement technique to decide management alternatives. Strong correlation between visual obstruction and vegetation weight was also obtained in a Kansas grassland by Robel et al. (1970) using a pole with alternating light-brown and white $1 \mathrm{dm}$ wide bands.

Interpretation of our data indicated that the visual obstruction technique was faster and more precise than the clip/weigh procedure when clipping and weighing 6 or fewer plots per transect. Less time was spent sampling 20 visual obstruction stations (25 minutes) compared to hand harvesting and processing 6 clipped plots $(45$ minutes) to obtain equal precision. With 


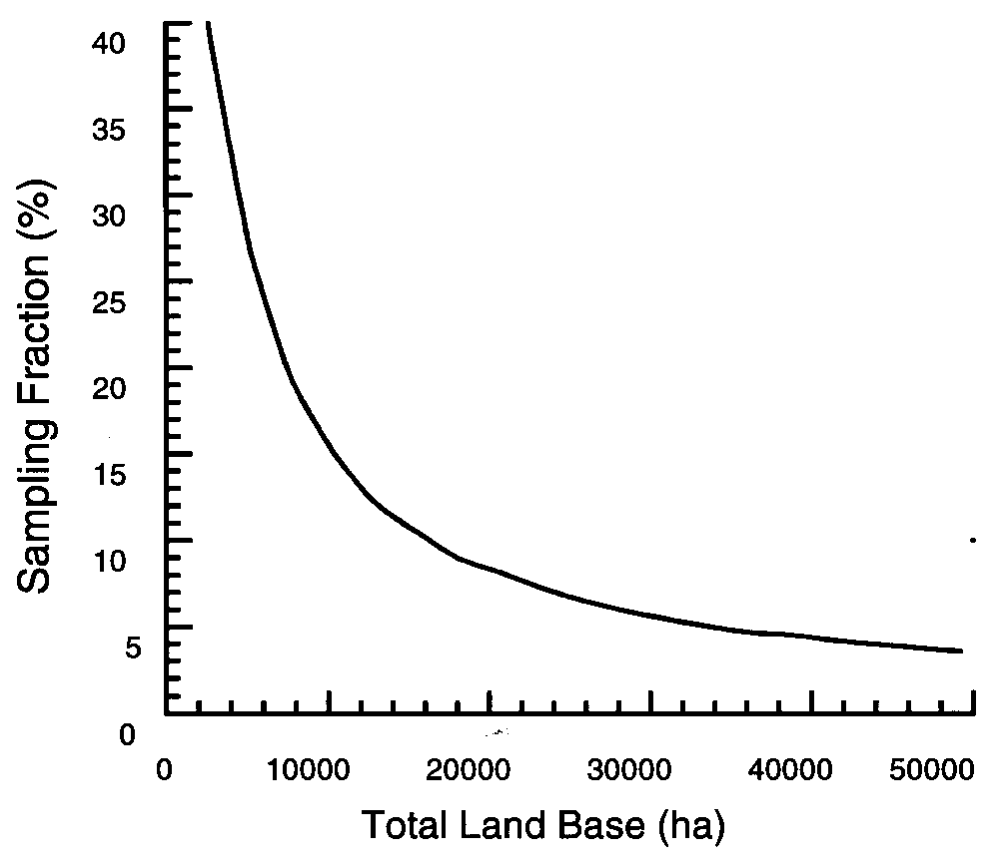

Fig. 5. Estimated percentage of total land base that should be sampled when applying the visual obstruction pole to large areas for monitoring purposes. The area to be sampled was divided into sections ( 259 ha). Each section was subdivided into quarter sections with one section randomly selected for placement of one transect. the visual obstruction technique less time was spent obtaining a visual obstruction estimate per transect; thus, the visual obstruction technique can be more economical to use when monitoring large grassland areas for average standing crop. Assessment of monitoring alternatives, using a minimum of $10 \%$ of total land base for sampling broad grasslands, showed that with option $\mathrm{A}$, the number of

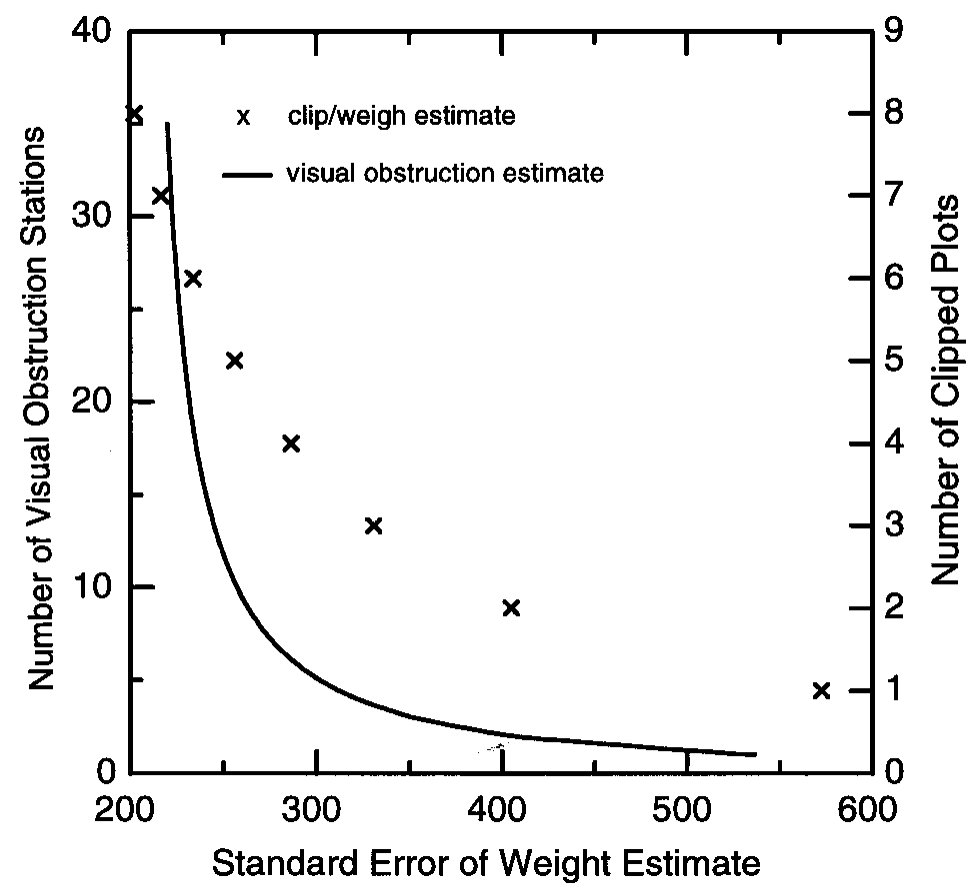

Fig. 6. Comparison of precision for weight estimates based on clip/weigh direct estimates and visual obstruction pole indirect estimates using a regression model. primary units increased to 72 which resulted in more sections included and better distribution throughout the entire land base. With option B, fewer primary units (18) were needed to sample the entire land base but more sampling subunits ( 3 transects) per section and resulted in better distribution within a section. Option A did not provide reliable estimates of visual obstruction or standing crop for a section or a few sections but it required lower sampling intensity than option $\mathrm{B}$, thus was less costly when estimating an average visual obstruction for a large area (e.g., SMNF 46,929 ha). Option B required more intensive sampling than option $\mathrm{A}$, so was more costly when dealing with a broad area but was capable of providing reliable estimates (standard error for individual section averaged 0.81 or \pm 1.33 with $80 \%$ confidence) of visual obstruction and standing crop for both an individual section or an entire land base. Increasing $n$ would increase the comparability of options A and B for describing the entire area while maintaining precision of estimates for individual units ( $80 \%$ confidence interval of $\pm 1.27 \mathrm{~cm}$ on average for our data).

\section{Application}

Visual obstruction (VOR) sampling can be conducted by 1 person following the procedure described by Robel et al. (1970). The pole (grey and white bands) should be placed vertically in the vegetation at arm's length to avoid trampling effects on the vegetation or biased sampling, and then spiked into the ground to stand freely. The top band totally obstructed is read and the measurement recorded. Visual obstruction readings are collected at stations along transects. The 4 VORs recorded for each cardinal direction are averaged for each station and then all stations are averaged for each transect. Transect averages are then applied separately in the regression model to obtain standing crop estimates. These same transect averages for visual obstruction can be used to estimate average amounts of residual material for wildlife nesting and thermal cover. For areas larger than 1,000 ha, we recommend option A where the transect estimate represents the section estimate. For small areas (one or a few sections), we recommend Option B where the section estimate should be the average of 3 transect estimates. For large areas, Figure 5 should be used to determine the percentage of total area (ha) to be sampled. 


\section{Conclusions}

The developed protocol should be used to adapt the visual obstruction technique for monitoring standing crop of extensive grassland areas. The regression equation described in this study is applicable to sandy lowland range sites of the Nebraska Sandhills. Other regression equations should be developed for other grassland types following the methodology developed in this paper. The visual obstruction technique is simple, cost effective, and provides dual information pertinent to livestock and wildlife management.

\section{Literature Cited}

Afifi, A.A. and V. Clark. 1990. Computer aided multivariate analysis, 2nd ed. Chapman \& Hall, New York, N.Y.

Bleed, A. and C.F. Flowerday. 1990. An atlas of the Sand Hills, 2nd ed. Conserv. and Surv. Division, Inst. Agr. Natur. Resour, Univ. Nebraska. Lincoln, Neb.

Chambers, J.M., W.S. Cleveland, B. Kleines, and P.A. Tukey. 1983. Graphical methods for data analysis. Duxbury Press, Boston, Mass.

Cochran, W.G. 1977. Sampling techniques, 3rd ed. John Wiley Sons, Inc., New York, N.Y.

Cook, C.W. and J. Stubbendieck. 1986. Range research: Basic problems and techniques, Rev. ed. Soc. Range Manage. Denver, Colo.
Cryer, J.D. 1986. Time series analysis. Duxbury Press, Boston, Mass.

Earle, D.F. and A.A. McGowan. 1979. Evaluation and calibration of an automated rising plate meter for estimating dry matter of pasture. Australian J. Agr. Anim. Husb. 19:337-343.

Freese F. 1960. Testing Accuracy. Forest Sci. 6:139-144.

Fuller W.A. 1987. Measurement error models. John Wiley Sons, Inc., New York, N.Y.

Gabriëls, P.C.J. and J.V.Van Den Berg. 1993. Calibration of two techniques for estimating herbage mass. Grass and Forage Sci. 48:329-335.

Higgins, K.F. 1986. A comparison of burn season effects on nesting birds in North Dakota mixed grass prairie. Prairie Natur. 18:219-228.

Higgins, K.F. and W.T. Barker 1982. Changes in vegetation structure in seeded nesting cover in the prairie pothole region. USDA, FWS, Spec. Sci. Rep., Wildl. 242:1-26.

Holmes, C.W. 1974. The Massey grass meter. Dairy Farming Annual (1974) 26-30.

Kleinbaum, D.G. and L.L. Kupper. 1978. Applied regression analysis and other multi variable methods. Duxbury Press, Wadsworth Pub. Co., Inc., Belmont, Calif.

Michell, P. and R.V. Large. 1983. The estimation of herbage mass of perennial ryegrass swards: a comparative evaluation of a rising plate meter and a single-probe capacitance meter calibrated at and above ground level. Grass and Forage Sci. 38:295-299.
National Climate Data Center. 1993. Climatological data annual summary for South Dakota, Vol. 98, No 13.

Pechanec, J.F. and G.D. Pickford. 1937. A weight estimate method for determination of range or pasture production. J. Amer. Soc. Agron. 29:894-904.

Pearson, R.L. and L.D. Miller. 1972. Remote spectral measurements as a method for determining plant cover. US/IBP grassland biome technical report No. 167, Colorado State University, Fort Collins, Colo.

Robel, R.J. 1966. Behavior and mobility studies on the greater prairie chicken of northeastern Kansas. Yearbook Amer. Phil. Soc. 365-368.

Robel, R.J., J.N. Briggs, A.D. Dayton, and L.C. Hulbert. 1970. Relationships between visual obstruction measurements and weight of grassland vegetation. J. Range Manage. 23:295-297.

SAS Institute Inc. 1989. SAS/STAT user's guide, version 6 , fourth edition, volume 1 , Cary, NC: SAS Institute Inc.

Slade, N.A., J.J. Cebula, and R.J. Robel. 1965. Accuracy and reliability of biotelemetric instruments used in animal movement studies in prairie grasslands of Kansas. Trans. Kans. Acad. Sci. 68:173-179.

USDA-SCS. 1993. Soil survey of Cherry County, Nebraska. Univ. Nebraska, Conserv. Surv. Divis. Lincoln, Neb.

Webb, W.L. 1942. A method for wildlife management mapping in forested areas. J. Wildl. Manage. 6:38-43. 